\title{
HEDGING AND THE COMPETITIVE FIRM UNDER AMBIGUOUS PRICE AND BACKGROUND RISK
}

\author{
Yusuke Osaki* Kit Pong Wong ${ }^{\dagger}$ and Long $Y i^{\ddagger}$ \\ *Faculty of Economics, Osaka Sangyo University, Japan, \\ ${ }^{\dagger}$ School of Economics and Finance, University of Hong Kong, Hong Kong and \\ ${ }^{\ddagger}$ Department of Finance and Decision Sciences, Hong Kong Baptist University, Hong Kong
}

\begin{abstract}
This paper examines the optimal production and hedging decisions of the competitive firm that possesses smooth ambiguity preferences and faces ambiguous price and background risk. The separation theorem holds in that the firm's optimal output level depends neither on the firm's attitude towards ambiguity nor on the incident to the underlying ambiguity. We derive necessary and sufficient conditions under which the full-hedging theorem holds and thus options are not used. When these conditions are violated, we show that the firm optimally uses options for hedging purposes if ambiguity is introduced to the price and background risk by means of mean-preserving-spreads. We as such show that options play a role as a hedging instrument over and above that of futures.
\end{abstract}

Keywords: futures, options, production, smooth ambiguity preferences

JEL classification numbers: D21, D81, G13

\section{INTRODUCTION}

Since the seminal work of Sandmo (1971), the theory of the competitive firm under price uncertainty has been extensively studied. One important strand of this literature is on the behavior of the firm when a futures market exists (Danthine, 1978; Feder et al., 1980; Holthausen, 1979), from which two notable results emanate. First, the separation theorem states that the firm's production decision depends neither on the firm's preferences nor on the underlying price distribution. Second, the full-hedging theorem asserts that the

\footnotetext{
${ }^{*}$ Correspondence: Kit Pong Wong, School of Economics and Finance, University of Hong Kong, Pokfulam Road, Hong Kong. Tel.: +852 2859 1044; Fax: +852 2548 1152; Email: kpwong@econ.hku.hk. The authors would like to thank Francis Breedon (the editor), Udo Broll, Peter Welzel, two anonymous referees, and seminar participants at the University of Regensburg for their helpful comments and suggestions. Osaki would like to acknowledge the research funding from Grant-in-Aid for Young Scientists (A) and Grant-inAid for Scientific Research (C). The usual disclaimer applies.
} 
firm should completely eliminate its exposure to the price risk by adopting a full-hedge if the futures market is unbiased. ${ }^{1}$ A corollary of the full-hedging theorem is that no other hedging instruments, options in particular, play a role that is over and above that of futures for hedging purposes (Battermann et al., 2000). ${ }^{2}$

The literature on additive background risk stems from the seminal work of Kihlstrom et al. (1981), Nachman (1982), and Ross (1981). ${ }^{3}$ Gollier and Pratt (1996) characterize necessary and sufficient conditions under which the introduction of additive background risk leads to more cautious behavior, which they refer to as "risk vulnerability." Franke et al. $(2006,2011)$ extend the results of Gollier and Pratt (1996) to characterize conditions on preferences that lead to more cautious behavior with additive and multiplicative background risk. Wong (2014) shows that the separation and full-hedging theorems are robust to the introduction of additive background risk.

In this paper, we adopt the premise that the competitive firm of Sandmo (1971) is unable to unambiguously assign probability distributions that uniquely describe the price and background risk. In other words, the firm faces ambiguity, or uncertainty in the sense of Knight (1921), about the price and background risk. ${ }^{4}$ Ambiguity averse preferences are supported by convincing evidence from many experiments (Chow and Sarin, 2001; Einhorn and Hogarth, 1986; Sarin and Weber, 1993) and surveys (Chesson and Viscusi, 2003; Viscusi and Chesson, 1999), which document that individuals prefer gambles with known rather than unknown probabilities. ${ }^{5}$

\footnotetext{
${ }^{1}$ The full-hedging theorem is analogous to a well-known result in the insurance literature that a risk-averse individual fully insures at an actuarially fair price (Mossin, 1968).

${ }^{2}$ Lapan et al. (1991) show that options are used by the competitive firm only when the futures price and/or option premiums are perceived by the firm as biased. Options as such appear to be a speculative device rather than a hedging instrument.

${ }^{3}$ Examples of additive background risk abound. Some of the initial wealth of the competitive firm may be held in risky assets and thus creates an additional source of uncertainty (Chavas, 1985). The fixed cost of the competitive firm may also be random because the firm's physical assets can be ruined by natural disasters or fire (Wong, 1996, 2014).

${ }^{4}$ Knight (1921) points out that ambiguity is fundamentally different from risk. Specifically, risk relates to objective uncertainty, where outcome probabilities are known or can be estimated with confidence. In contrast, ambiguity relates to subjective uncertainty, where outcome probabilities are unknown, and decision makers are not sure which estimated models are correct.

${ }^{5}$ Dated back to the Ellsberg's (1961) paradox, ambiguity has been alluded to the violation of the independence axiom, which is responsible for the decision criterion being linear in the outcome probabilities. See
} 
Klibanoff et al. (2005) have recently developed a powerful decision criterion known as "smooth ambiguity aversion" that is compatible with ambiguity averse preferences under uncertainty (hereafter referred to as the KMM model). The KMM model features the recursive structure that is far more tractable in comparison to other models of ambiguity such as the pioneering maxmin expected utility (or multiple-prior) model of Gilboa and Schmeidler (1989). ${ }^{6}$ Another nice feature of the KMM model is that the conventional techniques in the decision making under uncertainty are applicable in the context of ambiguity (Alary et al., 2013; Broll and Wong, 2015; Cherbonnier and Gollier, 2015; Gollier, 2011; Iwaki and Osaki, 2014; Snow, 2010, 2011; Taboga, 2005; Treich, 2010; Wong, 2015a, 2016a).

The KMM model represents ambiguity by a second-order probability distribution that captures the firm's uncertainty about which of the subjective beliefs govern the price and background risk. The KMM model then measures the firm's expected utility under ambiguity by taking the second-order expectation of a concave transformation of the first-order expected utility of profit conditional on each plausible subjective joint distribution of the price and background risk. ${ }^{7}$ While it is reasonable to assume that the firm regards the price and background risk to be independent of each other for given subjective beliefs, they are deemed to be second-order dependent when the subjective beliefs vary. This second-order dependence structure of the ambiguous price and background risk is crucial in determining the firm's production and hedging decisions.

Within the KMM model, we show that the separation theorem holds in that the firm's optimal output level depends neither on the firm's attitude towards ambiguity nor on the incident to the underlying ambiguity. This is because the firm can always sell the last unit of its output through the futures contracts. The marginal revenue as such is locked in at the predetermined futures price, which is equated to the marginal cost of production at the optimum. Hence, we extend the separation theorem to the case of smooth ambiguity

Dillenberger and Segal (2015) and Machina (2014).

${ }^{6}$ See Lien (2000) and Lien and Wang (2003) who adopt the maxmin expected utility model of Gilboa and Schmeidler (1989) to examine the competitive firm's production and hedging decisions.

${ }^{7}$ Skiadas (2013) shows that smooth ambiguity preferences can be approximated by preferences admitting an expected utility representation in continuous-time or high-frequency models under Brownian or Poisson uncertainty. 
preferences and in the presence of ambiguous price and background risk.

We derive necessary and sufficient conditions under which the full-hedging theorem holds. These conditions are rather strong. For example, they hold if the firm is risk neutral and the background risk has a constant conditional mean. In this case, the risk-neutral firm simply regards the background risk with a constant conditional mean as unambiguous. This is consistent with the findings of Wong (2015a) that the full-hedging theorem applies under smooth ambiguity preferences should the background risk be absent. When the necessary and sufficient conditions do not hold, options may play a role as a hedging instrument. Indeed, if ambiguity is introduced to the price and background risk by means of meanpreserving-spreads, we show that the firm optimally uses options for hedging purposes irrespective of whether the firm is ambiguity neutral or ambiguity averse. Since the fullhedging theorem holds when ambiguity is absent (Wong, 2014), the behavior of the firm is affected by the introduction of ambiguity even under ambiguity neutrality. This novel finding is driven by the second-order dependence structure between the ambiguous price and background risk, which is absent in the extant literature that focuses on a single source of ambiguity.

The rest of this paper is organized as follows. The next section delineates the KMM model of the competitive firm facing ambiguous price and background risk. Section III characterizes the firm's optimal production decision. Section IV derives the firm's optimal hedging decision. The final section concludes.

\section{THE MODEL}

We incorporate the KMM model into the competitive firm of Sandmo (1971). There is one period with two dates, 0 and 1 . At date 0 , the firm produces a single commodity according to a deterministic cost function, $C(Q)$, where $Q \geq 0$ is the output level and $C(Q)$ is compounded to date 1 . The firm's production technology exhibits decreasing returns to scale so that the cost function, $C(Q)$, satisfies that $C(0)=C^{\prime}(0)=0$, and $C^{\prime}(Q)>0$ and 
$C^{\prime \prime}(Q)>0$ for all $Q>0$.

At date 1 , the firm sells its entire output, $Q$, at the then prevailing per-unit price, $\tilde{P}$, which is a positive random variable not known ex ante. ${ }^{8}$ The price risk, $\tilde{P}$, is distributed according to an objective cumulative distribution function $(\mathrm{CDF}), F^{\circ}(P)$, over support $[\underline{P}, \bar{P}]$, where $0<\underline{P}<\bar{P}$. Besides the price risk, $\tilde{P}$, the firm faces other sources of risk that are aggregated into a single random variable, $\tilde{Z}$, which is referred to as the background risk. We assume that $\tilde{Z}$ is independent of $\tilde{P}$, and is additive in nature. The background risk, $\tilde{Z}$, is distributed according to an objective $\mathrm{CDF}, G^{\circ}(Z)$, over support $[\underline{Z}, \bar{Z}]$, where $\underline{Z}<\bar{Z} .^{9}$ We denote $\mathrm{E}_{F^{\circ}}(\cdot)$ and $\mathrm{E}_{G^{\circ}}(\cdot)$ as the expectation operators with respect to the objective CDFs, $F^{\circ}(P)$ and $G^{\circ}(Z)$, respectively.

While the background risk, $\tilde{Z}$, is neither hedgeable nor insurable, the firm can hedge against the price risk, $\tilde{P}$, by trading infinitely divisible futures and put option contracts at date 0 , each of which calls for delivery of one unit of the commodity at date $1 .{ }^{10}$ The futures price is predetermined at $P^{f}$ at date 0 , where $\underline{P}<P^{f}<\bar{P}$. The put option contracts have a single strike price, $K$, and an exogenously given option premium, $\Phi$, per contract, where $\underline{P}<K<\bar{P}$ and $\Phi>0$. The option premium, $\Phi$, is compounded to date 1 .

The firm's random profit at date 1 is given by

$$
\Pi(\tilde{P}, \tilde{Z})=\tilde{P} Q-C(Q)+\left(P^{f}-\tilde{P}\right) X+[\max (K-\tilde{P}, 0)-\Phi] Y+\tilde{Z}
$$

where $X$ is the number of the futures contracts sold (purchased if negative), and $Y$ is the number of the put option contracts purchased (sold if negative) by the firm at date 0 . We say that the firm's futures position, $X$, is an under-hedge, a full-hedge, or an over-hedge, depending on whether $X$ is smaller than, equal to, or greater than the output level, $Q$, respectively. The firm's put option position, $Y$, is a long (short) position if $Y>(<) 0$. The firm possesses a von Neumann-Morgenstern utility function, $u(\Pi)$, defined over its profit at

\footnotetext{
${ }^{8}$ Throughout the paper, random variables have a tilde $(\sim)$ while their realizations do not.

${ }^{9}$ We allow the background risk, $\tilde{Z}$, to have either a positive, zero, or negative mean.

${ }^{10}$ Because of the put-call parity, payoffs of any combinations of futures, calls, and puts can be replicated by any two of these three financial instruments, thereby rendering one of them to be redundant. As such, restricting the firm to use only futures and put option contracts is without any loss of generality.
} 
date $1, \Pi$, with $u^{\prime}(\Pi)>0$ and $u^{\prime \prime}(\Pi) \leq 0$. The firm is risk neutral or risk averse, depending on whether $u(\Pi)=\Pi$ or $u^{\prime \prime}(\Pi)<0$, respectively.

The firm faces ambiguity in that it is uncertain about the objective CDFs, $F^{\circ}(P)$ and $G^{\circ}(Z)$. Let $F(P \mid \theta)$ and $G(Z \mid \theta)$ be the firm's first-order subjective CDFs of $\tilde{P}$ and $\tilde{Z}$, respectively, where $\theta$ is the realization of an unknown parameter, $\tilde{\theta}$. The KMM model represents ambiguity by a second-order subjective CDF of $\tilde{\theta}, H(\theta)$, over support $[\underline{\theta}, \bar{\theta}]$ with $\underline{\theta}<\bar{\theta}$, which captures the firm's uncertainty about which of the first-order CDFs govern $\tilde{P}$ and $\tilde{Z}$. Following Gollier (2011), Snow (2010, 2011), and Wong (2015b, 2016b), we assume that the firm's ambiguous beliefs are unbiased in the following sense:

$$
\int_{\underline{\theta}}^{\bar{\theta}} F(P \mid \theta) \mathrm{d} H(\theta)=F^{\circ}(P),
$$

for all $P \in[\underline{P}, \bar{P}]$, and

$$
\int_{\underline{\theta}}^{\bar{\theta}} G(Z \mid \theta) \mathrm{d} H(\theta)=G^{\circ}(Z),
$$

for all $Z \in[\underline{Z}, \bar{Z}]$. We denote $\mathrm{E}_{F}(\cdot \mid \theta), \mathrm{E}_{G}(\cdot \mid \theta)$, and $\mathrm{E}_{H}(\cdot)$ as the expectation operators with respect to the subjective CDFs, $F(P \mid \theta), G(Z \mid \theta)$, and $H(\theta)$, respectively.

While the price risk, $\tilde{P}$, and the background risk, $\tilde{Z}$, are first-order independent given a fixed value of the parameter, $\theta$, they become second-order dependent as $\theta$ varies. To see this, we calculate the covariance between $A(\tilde{P})$ and $B(\tilde{Z})$ :

$$
\begin{aligned}
& \int_{\underline{\theta}}^{\bar{\theta}} \int_{\underline{P}}^{\bar{P}} \int_{\underline{Z}}^{\bar{Z}}\left\{A(P)-\mathrm{E}_{F^{\circ}}[A(\tilde{P})]\right\}\left\{B(Z)-\mathrm{E}_{G^{\circ}}[B(\tilde{Z})]\right\} \mathrm{d} F(P \mid \theta) \mathrm{d} G(Z \mid \theta) \mathrm{d} H(\theta) \\
& =\int_{\underline{\theta}}^{\bar{\theta}} \int_{\underline{P}}^{\bar{P}} \int_{\underline{Z}}^{\bar{Z}}\left\{A(P)-\mathrm{E}_{F}[A(\tilde{P}) \mid \theta]\right\}\left\{B(Z)-\mathrm{E}_{G}[B(\tilde{Z}) \mid \theta]\right\} \mathrm{d} F(P \mid \theta) \mathrm{d} G(Z \mid \theta) \mathrm{d} H(\theta) \\
& \quad+\int_{\underline{\theta}}^{\bar{\theta}}\left\{\mathrm{E}_{F}[A(\tilde{P}) \mid \theta]-\mathrm{E}_{F^{\circ}}[A(\tilde{P})]\right\}\left\{\mathrm{E}_{G}[B(\tilde{Z}) \mid \theta]-\mathrm{E}_{G^{\circ}}[B(\tilde{Z})]\right\} \mathrm{d} H(\theta) \\
& =\operatorname{Cov}_{H}\left\{\mathrm{E}_{F}[A(\tilde{P}) \mid \tilde{\theta}], \mathrm{E}_{G}[B(\tilde{Z}) \mid \tilde{\theta}]\right\},
\end{aligned}
$$


where $A(\cdot)$ and $B(\cdot)$ are two arbitrarily chosen functions, $\operatorname{Cov}_{H}(\cdot, \cdot)$ is the covariance operator with respect to the second-order CDF, $H(\theta)$, and we have used Eqs. (2) and (3). It follows from Eq. (4) that $A(\tilde{P})$ and $B(\tilde{Z})$ are second-order positively (negatively) dependent if $\operatorname{Cov}_{H}\left\{\mathrm{E}_{F}[A(\tilde{P}) \mid \tilde{\theta}], \mathrm{E}_{G}[B(\tilde{Z}) \mid \tilde{\theta}]\right\}>(<) 0$. For example, this is the case when changes in $\theta$ affect the first-order expected values of $A(\tilde{P})$ and $B(\tilde{Z}), \mathrm{E}_{F}[A(\tilde{P}) \mid \theta]$ and $\mathrm{E}_{G}[B(\tilde{Z}) \mid \theta]$, in the same direction (opposite directions) for all $\theta \in[\underline{\theta}, \bar{\theta}]$. We can justify the second-order dependence structure between $\tilde{P}$ and $\tilde{Z}$ by a learning framework, whereby the first-order priors are the Bayesian posterior distributions, and the second-order priors are the unconditional likelihoods. In this context, we can interpret $\theta$ as a latent business cycle indicator that affects the price and background risk simultaneously.

The recursive structure of the KMM model implies that we can compute the firm's expected utility under ambiguity in three steps. First, we calculate the firm's expected utility for each first-order joint CDF of $\tilde{P}$ and $\tilde{Z}$ :

$$
U(\theta)=\int_{\underline{P}}^{\bar{P}} \int_{\underline{Z}}^{\bar{Z}} u[\Pi(P, Z)] \mathrm{d} F(P \mid \theta) \mathrm{d} G(Z \mid \theta),
$$

where $\Pi(P, Z)$ is given by Eq. (1). Second, we transform each first-order expected utility obtained in Eq. (5) by an ambiguity function, $\varphi(U)$, where $\varphi^{\prime}(U)>0$ and $U$ is the firm's utility level. Finally, we take the expectation of the transformed first-order expected utility obtained in the second step with respect to the second-order CDF of $\tilde{\theta}$. The firm's ex-ante decision problem as such is given by

$$
\max _{Q \geq 0, X, Y} \int_{\underline{\theta}}^{\bar{\theta}} \varphi[U(\theta)] \mathrm{d} H(\theta),
$$

where $U(\theta)$ is defined by Eq. (5). Inspection of the objective function of program (6) reveals that the effect of ambiguity, represented by the second-order CDF, $H(\theta)$, and the effect of ambiguity preferences, represented by the shape of the ambiguity function, $\varphi(U)$, can be separated and thus studied independently.

We say that the firm is ambiguity averse if, for any given triple of output level and hedge position, $(Q, X, Y)$, the objective function of program (6) decreases when the firm's 
ambiguous beliefs, specified by $H(\theta)$, change in a way that induces a mean-preserving-spread in the distribution of the firm's first-order expected utility. According to this definition, Klibanoff et al. (2005) show that ambiguity aversion implies that the ambiguity function, $\varphi(U)$, is concave in $U .{ }^{11}$ The firm is ambiguity neutral or ambiguity averse, depending on whether $\varphi(U)=U$ or $\varphi^{\prime \prime}(U)<0$, respectively.

The first-order conditions for program (6) are given by

$$
\begin{aligned}
& \int_{\underline{\theta}}^{\bar{\theta}} \int_{\underline{P}}^{\bar{P}} \int_{\underline{Z}}^{\bar{Z}} \varphi^{\prime}\left[U^{*}(\theta)\right] u^{\prime}\left[\Pi^{*}(P, Z)\right]\left[P-C^{\prime}\left(Q^{*}\right)\right] \mathrm{d} F(P \mid \theta) \mathrm{d} G(Z \mid \theta) \mathrm{d} H(\theta)=0, \\
& \int_{\underline{\theta}}^{\bar{\theta}} \int_{\underline{P}}^{\bar{P}} \int_{\underline{Z}}^{\bar{Z}} \varphi^{\prime}\left[U^{*}(\theta)\right] u^{\prime}\left[\Pi^{*}(P, Z)\right]\left(P^{f}-P\right) \mathrm{d} F(P \mid \theta) \mathrm{d} G(Z \mid \theta) \mathrm{d} H(\theta)=0
\end{aligned}
$$

and

$$
\int_{\underline{\theta}}^{\bar{\theta}} \int_{\underline{P}}^{\bar{P}} \int_{\underline{Z}}^{\bar{Z}} \varphi^{\prime}\left[U^{*}(\theta)\right] u^{\prime}\left[\Pi^{*}(P, Z)\right][\max (K-P, 0)-\Phi] \mathrm{d} F(P \mid \theta) \mathrm{d} G(Z \mid \theta) \mathrm{d} H(\theta)=0,
$$

where an asterisk $\left(^{*}\right)$ indicates an optimal level. The second-order conditions for program (6) are satisfied given the assumed properties of $\varphi(U), u(\Pi)$, and $C(Q)$.

\section{OPTIMAL PRODUCTION DECISION}

Adding Eqs. (7) and (8) yields

$$
\int_{\underline{\theta}}^{\bar{\theta}} \int_{\underline{P}}^{\bar{P}} \int_{\underline{Z}}^{\bar{Z}} \varphi^{\prime}\left[U^{*}(\theta)\right] u^{\prime}\left[\Pi^{*}(P, Z)\right]\left[P^{f}-C^{\prime}\left(Q^{*}\right)\right] \mathrm{d} F(P \mid \theta) \mathrm{d} G(Z \mid \theta) \mathrm{d} H(\theta)=0,
$$

It follows from $\varphi^{\prime}(U)>0$ and $u^{\prime}(\Pi)>0$ that Eq. (10) reduces to $C^{\prime}\left(Q^{*}\right)=P^{f}$, thereby invoking our first proposition.

Proposition 1. Given that the ambiguity-averse competitive firm can hedge against the ambiguous price risk, $\tilde{P}$, by trading the futures and put option contracts, the firm's optimal

\footnotetext{
${ }^{11}$ When $\varphi(U)=-\eta^{-1} \exp (-\eta U)$, Klibanoff et al. (2005) show that the maxmin expected utility model of Gilboa and Schmeidler (1989) is the limiting case as the coefficient of absolute ambiguity aversion, $\eta$, approaches infinity under some conditions.
} 
output level, $Q^{*}$, is the one that equates the marginal cost of production, $C^{\prime}\left(Q^{*}\right)$, to the predetermined futures price, $P^{f}$.

The intuition for Proposition 1 is as follows. Since the firm can always sell the last unit of its output through the futures contracts at the predetermined futures price, $P^{f}$, the usual optimality condition applies in that the marginal cost of production, $C^{\prime}\left(Q^{*}\right)$, must be equated to the known marginal revenue, $P^{f}$, which determines the optimal output level, $Q^{*}$. This result holds irrespective of whether the put option contracts are available to the firm for hedging purposes or not.

An immediate implication of Proposition 1 is that the firm's optimal production decision depends neither on the firm's attitude towards ambiguity nor on the incident to the underlying ambiguity. Proposition 1 as such extends the separation theorem of Danthine (1978), Feder et al. (1980), and Holthausen (1979) to the case of smooth ambiguity preferences and in the presence of ambiguous price and background risk. ${ }^{12}$

\section{OPTIMAL HEDGING DECISION}

To focus on the firm's pure hedging motive, we assume henceforth that the futures and put option contracts are fairly priced in that

$$
P^{f}=\mathrm{E}_{F^{\circ}}(\tilde{P})=\int_{\underline{\theta}}^{\bar{\theta}} \mathrm{E}_{F}(\tilde{P} \mid \theta) \mathrm{d} H(\theta)
$$

and

$$
\Phi=\mathrm{E}_{F^{\circ}}[\max (K-\tilde{P}, 0)]=\int_{\underline{\theta}}^{\bar{\theta}} \mathrm{E}_{F}[\max (K-\tilde{P}, 0) \mid \theta] \mathrm{d} H(\theta) .
$$

Eqs. (11) and (12) imply that $P^{f}$ and $\Phi$ are set equal to the unconditional expected values of $\tilde{P}$ and $\max (K-\tilde{P}, 0)$ with respect to both the objective and subjective CDFs of $\tilde{P}$, respectively.

\footnotetext{
${ }^{12}$ Wong (2016) shows that the separation theorem fails to hold should the ambiguous background risk be multiplicative in nature.
} 
Differentiating the objective function of program (6) with respect to $X$, and evaluating the resulting derivative at $Q=Q^{*}, X=Q^{*}$, and $Y=0$ yields

$$
\begin{aligned}
& \left.\frac{\partial}{\partial X} \int_{\underline{\theta}}^{\bar{\theta}} \varphi[U(\theta)] \mathrm{d} H(\theta)\right|_{Q=Q^{*}, X=Q^{*}, Y=0} \\
& =\int_{\underline{\theta}}^{\bar{\theta}} \varphi^{\prime}\left\{\mathrm{E}_{G}\left[u\left(\Pi^{*}+\tilde{Z}\right) \mid \theta\right]\right\} \mathrm{E}_{G}\left[u^{\prime}\left(\Pi^{*}+\tilde{Z}\right) \mid \theta\right]\left[\mathrm{E}_{F^{\circ}}(\tilde{P})-\mathrm{E}_{F}(\tilde{P} \mid \theta)\right] \mathrm{d} H(\theta) \\
& =-\operatorname{Cov}_{H}\left\{\varphi^{\prime}\left\{\mathrm{E}_{G}\left[u\left(\Pi^{*}+\tilde{Z}\right) \mid \tilde{\theta}\right]\right\} \mathrm{E}_{G}\left[u^{\prime}\left(\Pi^{*}+\tilde{Z}\right) \mid \tilde{\theta}\right], \mathrm{E}_{F}(\tilde{P} \mid \tilde{\theta})\right\}
\end{aligned}
$$

where $\Pi^{*}=\mathrm{E}_{F^{\circ}}(\tilde{P}) Q^{*}-C\left(Q^{*}\right)$, and the second equality follows from Eq. $(2)$ and the property of the covariance operator, $\operatorname{Cov}_{H}(\cdot, \cdot) \cdot{ }^{13}$ Likewise, we differentiate the objective function of program (6) with respect to $Y$, and evaluate the resulting derivative at $Q=Q^{*}$, $X=Q^{*}$, and $Y=0$ to yield

$$
\begin{aligned}
& \left.\frac{\partial}{\partial Y} \int_{\underline{\theta}}^{\bar{\theta}} \varphi[U(\theta)] \mathrm{d} H(\theta)\right|_{Q=Q^{*}, X=Q^{*}, Y=0} \\
& =\operatorname{Cov}_{H}\left\{\varphi^{\prime}\left\{\mathrm{E}_{G}\left[u\left(\Pi^{*}+\tilde{Z}\right) \mid \tilde{\theta}\right]\right\} \mathrm{E}_{G}\left[u^{\prime}\left(\Pi^{*}+\tilde{Z}\right) \mid \tilde{\theta}\right], \mathrm{E}_{F}[\max (K-\tilde{P}, 0) \mid \tilde{\theta}]\right\}
\end{aligned}
$$

Using Eqs. (13) and (14), the full-hedging theorem holds, i.e., $X^{*}=Q^{*}$ and $Y^{*}=0$, if, and only if, the following two conditions hold simultaneously:

$$
\operatorname{Cov}_{H}\left\{\varphi^{\prime}\left\{\mathrm{E}_{G}\left[u\left(\Pi^{*}+\tilde{Z}\right) \mid \tilde{\theta}\right]\right\} \mathrm{E}_{G}\left[u^{\prime}\left(\Pi^{*}+\tilde{Z}\right) \mid \tilde{\theta}\right], \mathrm{E}_{F}(\tilde{P} \mid \tilde{\theta})\right\}=0
$$

and

$$
\operatorname{Cov}_{H}\left\{\varphi^{\prime}\left\{\mathrm{E}_{G}\left[u\left(\Pi^{*}+\tilde{Z}\right) \mid \tilde{\theta}\right]\right\} \mathrm{E}_{G}\left[u^{\prime}\left(\Pi^{*}+\tilde{Z}\right) \mid \tilde{\theta}\right], \mathrm{E}_{F}[\max (K-\tilde{P}, 0) \mid \tilde{\theta}]\right\}=0
$$

where $\Pi^{*}=\mathrm{E}_{F^{\circ}}(\tilde{P}) Q^{*}-C\left(Q^{*}\right)$. The term, $\varphi^{\prime}\left\{\mathrm{E}_{G}\left[u\left(\Pi^{*}+\tilde{Z}\right) \mid \theta\right]\right\} u^{\prime}\left(\Pi^{*}+\tilde{Z}\right)$, is the marginal ambiguity under a full-hedge and zero-option position. Using Eq. (4), conditions (15) and (16) simply say that this marginal ambiguity is neither second-order dependent on the

\footnotetext{
${ }^{13}$ For any two random variables, $\tilde{X}$ and $\tilde{Y}$, we have $\operatorname{Cov}_{H}(\tilde{X}, \tilde{Y})=\mathrm{E}_{H}(\tilde{X} \tilde{Y})-\mathrm{E}_{H}(\tilde{X}) \mathrm{E}_{H}(\tilde{Y})$.
} 
payoff of the futures contracts, $\tilde{P}-P^{f}$, nor second-order dependent on the payoff of the put option contracts, $\max (K-\tilde{P}, 0)$, respectively. Given that covariances can be interpreted as marginal variances, conditions (15) and (16) ensure that the firm has already minimized the variability of its utility under ambiguity by adopting the full-hedge and zero-option position. We as such establish the following proposition.

Proposition 2. Given that the ambiguity-averse competitive firm can hedge against the ambiguous price risk, $\tilde{P}$, by trading the fairly priced futures and put option contracts, the firm optimally opts for a full-hedge, i.e., $X^{*}=Q^{*}$, and uses no options, i.e., $Y^{*}=0$, if, and only if, the marginal ambiguity, $\varphi^{\prime}\left\{\mathrm{E}_{G}\left[u\left(\Pi^{*}+\tilde{Z}\right) \mid \theta\right]\right\} u^{\prime}\left(\Pi^{*}+\tilde{Z}\right)$, is neither second-order dependent on the payoff of the futures contracts, $\tilde{P}-P^{f}$, nor second-order dependent on the payoff of the put option contracts, $\max (K-\tilde{P}, 0)$.

In the absence of the ambiguous background risk, Eqs. (15) and (16) hold trivially, which is consistent with the finding of Wong (2015a) that the full-hedging theorem applies when the price risk is the only source of ambiguity. In the presence of the background risk, however, Eqs. (15) and (16) may or may not hold simultaneously. To see this, we consider the case that the firm is risk neutral, i.e., $u(\Pi)=\Pi$. In this case, Eqs. (15) and (16) reduce to

$$
\operatorname{Cov}_{H}\left\{\varphi^{\prime}\left[\Pi^{*}+\mathrm{E}_{G}(\tilde{Z} \mid \tilde{\theta})\right], \mathrm{E}_{F}(\tilde{P} \mid \tilde{\theta})\right\}=0
$$

and

$$
\operatorname{Cov}_{H}\left\{\varphi^{\prime}\left[\Pi^{*}+\mathrm{E}_{G}(\tilde{Z} \mid \tilde{\theta})\right], \mathrm{E}_{F}[\max (K-\tilde{P}, 0) \mid \tilde{\theta}]\right\}=0
$$

respectively. If the first-order expected background risk, $\mathrm{E}_{G}(\tilde{Z} \mid \theta)$, is preserved as $\theta$ varies, i.e., $\mathrm{E}_{G}(\tilde{Z} \mid \theta)$ is a constant for all $\theta \in[\underline{\theta}, \bar{\theta}]$, it is evident that Eqs. (17) and (18) hold simultaneously, thereby rendering the validity of the full-hedging theorem.

To show that Eqs. (15) and (16) need not hold simultaneously so that the firm optimally uses options for hedging purposes, we focus on the case that the first-order expected price 
risk, $\mathrm{E}_{F}(\tilde{P} \mid \theta)$, is preserved as $\theta$ varies, i.e., $\mathrm{E}_{F}(\tilde{P} \mid \theta)$ is a constant for all $\theta \in[\underline{\theta}, \bar{\theta}]$. Of course, in this case the firm has to be risk averse to ensure that the futures contracts play a hedging role. It is evident that the right-hand side of Eq. (13) vanishes so that a full-hedge, i.e., $X=Q^{*}$, is optimal should the firm use no options, i.e., $Y=0$. It then follows from Eqs. (9) and (14) and the second-order conditions for program (6) that $Y^{*}>(<) 0$ if, and only if,

$$
\operatorname{Cov}_{H}\left\{\varphi^{\prime}\left\{\mathrm{E}_{G}\left[u\left(\Pi^{*}+\tilde{Z}\right) \mid \tilde{\theta}\right]\right\} \mathrm{E}_{G}\left[u^{\prime}\left(\Pi^{*}+\tilde{Z}\right) \mid \tilde{\theta}\right], \mathrm{E}_{F}[\max (K-\tilde{P}, 0) \mid \tilde{\theta}]\right\}>(<) 0
$$

where $\Pi^{*}=\mathrm{E}_{F^{\circ}}(\tilde{P}) Q^{*}-C\left(Q^{*}\right)$. The term, $\varphi^{\prime}\left\{\mathrm{E}_{G}\left[u\left(\Pi^{*}+\tilde{Z}\right) \mid \theta\right]\right\} u^{\prime}\left(\Pi^{*}+\tilde{Z}\right)$, is the marginal ambiguity under a full-hedge and zero-option position. Using Eq. (4), condition (19) states that this marginal ambiguity is second-order positively (negatively) dependent on the payoff of the put option contracts, $\max (K-\tilde{P}, 0)$. To further reduce the variability of its utility under ambiguity, the firm is induced to opt for a long (short) put option position, thereby invoking the following proposition.

Proposition 3. Given that the ambiguity-averse competitive firm can hedge against the ambiguous price risk, $\tilde{P}$, by trading the fairly priced futures and put option contracts, and that the first-order expected price risk, $\mathrm{E}_{F}(\tilde{P} \mid \theta)$, is preserved as the parameter, $\theta$, varies, the firm optimally opts for a long (short) put option position, i.e., $Y^{*}>(<) 0$, if, and only if, the marginal ambiguity, $\varphi^{\prime}\left\{\mathrm{E}_{G}\left[u\left(\Pi^{*}+\tilde{Z}\right) \mid \theta\right]\right\} u^{\prime}\left(\Pi^{*}+\tilde{Z}\right)$, is second-order positively (negatively) dependent on the payoff of the put option contracts, $\max (K-\tilde{P}, 0)$.

To show that condition (19) holds in non-trivial circumstances, we consider the case that an increase in $\theta$ induces a mean-preserving-spread increase (decrease) in risk to the firstorder CDF, $F(P \mid \theta)$, and a mean-preserving-spread increase in risk to the first-order CDF, $G(Z \mid \theta)$, in the sense of Rothschild and Stiglitz (1970). Since $\max (K-P, 0)$ is convex in $P$, it follows from Rothschild and Stiglitz (1971) that $\mathrm{E}_{F}[\max (K-\tilde{P}, 0) \mid \theta]$ increases (decreases) with an increase in $\theta$. Risk aversion implies that $\mathrm{E}_{G}\left[u\left(\Pi^{*}+\tilde{Z}\right) \mid \theta\right]$ decreases with an increase in $\theta$. It then follows from ambiguity aversion that $\varphi^{\prime}\left\{\mathrm{E}_{G}\left[u\left(\Pi^{*}+\tilde{Z}\right) \mid \theta\right]\right\}$ increases with an 
increase in $\theta$. If the firm's utility function exhibits prudence, i.e., $u^{\prime \prime \prime}(\Pi)>0$, in the sense of Kimball (1993), $\mathrm{E}_{G}\left[u^{\prime}\left(\Pi^{*}+\tilde{Z}\right) \mid \theta\right]$ increases with an increase in $\theta$. Hence, we conclude that $\varphi^{\prime}\left\{\mathrm{E}_{G}\left[u\left(\Pi^{*}+\tilde{Z}\right) \mid \theta\right]\right\} \mathrm{E}_{G}\left[u^{\prime}\left(\Pi^{*}+\tilde{Z}\right) \mid \theta\right]$ increases with an increase in $\theta$ given that $u(\Pi)$ exhibits both risk aversion and prudence. In this case, condition (19) holds so that $Y^{*}>(<) 0$. It is worth mentioning that $Y^{*}>(<) 0$ even when the firm is ambiguity neutral, i.e., $\varphi(U)=U$.

One novel implication from Proposition 3 is in order. Suppose that there is no ambiguity, i.e., the firm knows the objective $\operatorname{CDFs}, F^{\circ}(P)$ and $G^{\circ}(Z)$. In this case, Eqs. (15) and (16) hold trivially so that the full-hedging theorem applies in that $X^{*}=Q^{*}$ and $Y^{*}=0$. Introducing ambiguity into the price and background risk by means of mean-preservingspreads induces the firm to optimally use options even when the firm is ambiguity neutral, as is shown above. The hedging role of options arises because the ambiguous background risk affects the firm's marginal utility, making the latter second-order dependent on the payoff of options. This is in stark contrast to the extant literature that focuses on a single source of ambiguity, which shows that the behavior of an ambiguity-neutral decision maker is unaffected by the introduction of, or changes in, ambiguity.

\section{CONCLUSION}

This paper examines the production and hedging decisions of the competitive firm under ambiguous price and background risk. The firm's preferences exhibit smooth ambiguity aversion developed by Klibanoff et al. (2005). Within the KMM model, ambiguity is represented by a second-order probability distribution that captures the firm's uncertainty about which of the subjective beliefs govern the price and background risk. On the other hand, ambiguity preferences are modeled by the second-order expectation of a concave transformation of the first-order expected utility of profit conditional on each plausible subjective joint distribution of the price and background risk.

Within the KMM model, we show that the firm's optimal production decision is independent of the firm's smooth ambiguity preferences and of the underlying ambiguous price 
and background risk, thereby invoking the separation theorem. We derive necessary and sufficient conditions under which the full-hedging theorem holds. When these conditions do not hold, we show that the firm optimally uses options for hedging purposes if ambiguity is introduced to the price and background risk by means of mean-preserving-spreads. We as such provide a rationale for the hedging role of options under smooth ambiguity preferences and ambiguous price and background risk.

\section{REFERENCES}

Alary, D., Gollier, C. and Treich, N. (2013). 'The effect of ambiguity aversion on insurance and self-protection', Economic Journal, 123, pp. 1188-202.

Battermann, H. L., Braulke, M., Broll, U. and Schimmelpfennig, J. (2000). 'The preferred hedge instrument', Economics Letters, 66, pp. 85-91.

Broll, U. and Wong, K. P. (2015). 'The incentive to trade under ambiguity aversion', Journal of Economic Asymmetries, 12, pp. 190-6.

Chavas, J.-P. (1985). 'On the theory of the competitive firm under uncertainty when initial wealth is random', Southern Economic Journal, 51, pp. 818-27.

Chesson, H. W. and Viscusi, W. K. (2003). 'Commonalities in time and ambiguity aversion for long-term risks', Journal of Risk and Uncertainty, 24, pp. 57-71.

Cherbonnier, F. and Gollier, C. (2015). 'Decreasing aversion under ambiguity', Journal of Economic Theory, 157, pp. 606-23.

Chow, C. C. and Sarin, R. K. (2001). 'Comparative ignorance and the Ellsberg Paradox', Journal of Risk and Uncertainty, 22, pp. 129-39.

Danthine, J.-P. (1978). 'Information, futures prices, and stabilizing speculation', Journal of Economic Theory, 17, pp. 79-98.

Dillenberger, D. and Segal, U. (2015). 'Recursive ambiguity and Machina's examples', 
International Economic Review, 56, pp. 55-61.

Einhorn, H. J. and Hogarth, R. M. (1986). 'Decision making under ambiguity', Journal of Business, 59, pp. S225-50.

Ellsberg, D. (1961). 'Risk, ambiguity, and the Savage axioms', Quarterly Journal of Economics, 75, pp. 643-69.

Feder, G., Just, R. E. and Schmitz, A. (1980). 'Futures markets and the theory of the firm under price uncertainty', Quarterly Journal of Economics, 94, pp. 317-28.

Franke, G., Schlesinger, H. and Stapleton, R. C. (2006). 'Multiplicative background risk', Management Science, 52, pp. 146-53.

Franke, G., Schlesinger, H. and Stapleton, R. C. (2011). 'Risk taking with additive and multiplicative background risks', Journal of Economic Theory, 146, pp. 1547-68.

Gilboa, I. and Schmeidler, D. (1989). 'Maxmin expected utility with a non-unique prior', Journal of Mathematical Economics, 18, pp. 141-53.

Gollier, C. (2011). 'Portfolio choices and asset prices: the comparative statics of ambiguity aversion', Review of Economic Studies, 78, pp. 1329-44.

Gollier, C., Pratt, J. W. (1996). 'Risk vulnerability and the tempering effect of background risk', Econometrica, 64, pp. 1109-1124.

Holthausen, D. M. (1979). 'Hedging and the competitive firm under price uncertainty', American Economic Review, 69, pp. 989-95.

Iwaki, H. and Osaki, Y. (2014). 'The dual theory of the smooth ambiguity model', Economic Theory, 56, pp. 275-89.

Kihlstrom, R. E., Romer, D., Williams, S. (1981). 'Risk aversion with random initial wealth', Econometrica, 49, pp. 911-920.

Kimball, M. S. (1993). 'Standard risk aversion', Econometrica, 61, pp. 589-611.

Klibanoff, P., Marinacci, M. and Mukerji, S. (2005). 'A smooth model of decision making 
under ambiguity', Econometrica, 73, pp. 1849-92.

Knight, F. H. (1921). Risk, Uncertainty and Profit. Boston: Houghton Mifflin.

Lapan, H., Moschini, G. and Hanson, S. D. (1991). 'Production, hedging, and speculative decisions with options and futures markets', American Journal of Agricultural Economics, 73, pp. 66-74.

Lien, D. (2000). 'Production and hedging under Knightian uncertainty', Journal of Futures Markets, 20, pp. 397-404.

Lien, D. and Wang, Y. (2003). 'Futures market equilibrium under Knightian uncertainty', Journal of Futures Markets, 23, pp. 701-18.

Machina, M. J. (2014). 'Ambiguity aversion with three or more outcomes', American Economic Review, 104, pp. 3814-40.

Mossin, J. (1968). 'Aspects of rational insurance purchasing', Journal of Political Economy, 76, pp. 553-68.

Nachman, D. C. (1982). 'Preservation of 'more risk averse' under expectations', Journal of Economic Theory, 28, pp. 361-368.

Ross, S. A. (1981). 'Some stronger measures of risk aversion in the small and the large with applications', Econometrica, 49, pp. 621-638.

Rothschild, M. and Stiglitz, J. E. (1970). 'Increasing risk I: A definition', Journal of Economic Theory, 2, pp. 225-43.

Rothschild, M. and Stiglitz, J. E. (1971). 'Increasing risk II: Its economic consequences', Journal of Economic Theory, 3, pp. 66-84.

Sandmo, A. (1971). 'On the theory of the competitive firm under price uncertainty', American Economic Review, 61, pp. 65-73.

Sarin, R. K. and Weber, M. (1993). 'Effects of ambiguity in market experiments', Management Science, 39, pp. 602-15. 
Skiadas, C. (2013). 'Smooth ambiguity aversion toward small risks and continuous-time recursive utility', Journal of Political Economy, 121, pp. 775-92.

Snow, A. (2010). 'Ambiguity and the value of information', Journal of Risk and Uncertainty, 40, pp. 133-45.

Snow, A. (2011). 'Ambiguity aversion and the propensities for self-insurance and selfprotection', Journal of Risk and Uncertainty, 42, pp. 27-43.

Taboga, M. (2005). 'Portfolio selection with two-stage preferences', Finance Research Letters, 2, pp. 152-64.

Treich, N. (2010). 'The value of a statistical life under ambiguity aversion', Journal of Environmental Economics and Management, 59, pp. 15-26.

Viscusi, W. K. and Chesson, H. W. (1999). 'Hopes and fears: the conflicting effects of risk ambiguity', Theory and Decision, 47, pp. 153-78.

Wong, K. P. (1996). 'Background risk and the theory of the competitive firm under uncertainty', Bulletin of Economic Research, 48, pp. 241-51.

Wong, K. P. (2014). 'Hedging and the competitive firm under correlated price and background risk', Decisions in Economics and Finance, 37, pp. 329-40.

Wong, K. P. (2015a). 'A smooth ambiguity model of the competitive firm', Bulletin of Economic Research, 67, pp. S97-110.

Wong, K. P. (2015b). 'Ambiguity and the value of hedging', Journal of Futures Markets, 35, pp. 839-48.

Wong, K. P. (2016a). 'Ambiguity and the multinational firm', International Review of Economics and Finance, 43, pp. 404-14.

Wong, K. P. (2016b). 'Production and hedging under smooth ambiguity preferences', Journal of Futures Markets, 36, pp. 506-18. 